\title{
Licensing and prescribing biosimilars in Australia
}

\author{
Professor David A Power, MD, PhD, FRCP, FRACP
}

Some years ago, Australian regulatory authorities decided to follow the path laid down by the European Medicines Agency in adopting a process for approval of biosimilars. This has been a largely successful process, resulting in the licensing of biosimilars for many peptides, especially epoetin and granulocyte colony-stimulating factor (G-CSF). Aside from the availability of multiple agents, pricing has been significantly affected by the ability of hospital pharmacies to tender for supply of a particular drug, restricting choice in their hospitals to one of a number of agents with identical or similar pharmacodynamics and mechanisms of action. Increasingly, however, patients are opting to have supplies of these expensive drugs delivered by community pharmacies. This has the potential to dilute cost savings and increase the complexity of pharmacovigilance.

Keywords: Australia, biosimilars, Pharmaceutical Benefits Scheme, TGA

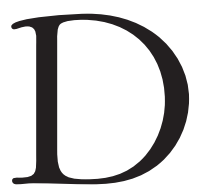
espite ongoing debate regarding safety and costeffectiveness [1-3], it is generally accepted that the emergence of biosimilars has the potential to deliver a significant financial advantage to healthcare providers. The problem has been to license these products rapidly but with sufficient assessment to ensure safety and efficacy. These products are not identical to the innovator drugs that preceded them, so there has to be a balance between rigorous assessment and the avoidance of unreasonable delay in bringing them to market. It was these considerations that lead the European Medicines Agency (EMA) to propose a novel method for bringing these drugs to market, while accepting that a more complex process was required than that used for generic forms of simpler drugs [4].
The Australian context

In Australia, licensing of drugs is performed by the Therapeutic Goods Administration (TGA), a government body operating under a national legislative framework that evaluates drugs for safety and efficacy and then licenses them for use in Australia. It is the Australian equivalent of EMA in the EU or FDA in the United States. Once licensed by TGA, there is a system of cost subsidy for drugs, called the Pharmaceutical Benefits Scheme (PBS), whose role is to balance cost and the contribution of an individual drug to an improved outcome for patients. This dual approval process prior to listing of a drug on the list for subsidy strongly influences use of drugs in Australia. It has been relatively unusual for a drug to be widely prescribed before it is listed on the PBS, although delays in PBS listing of expensive therapies can increase non-PBS use.
The Australian healthcare system

Australia has both a universal healthcare system, free at the point of delivery, and a private healthcare system that run side by side. Patients within either system can cross to the other. The federal or national government has generally subsidized drugs, although they are not free, but subsidy does not occur for drugs used by hospital inpatients. The Australian Government, therefore, subsidizes the vast majority of drugs used by outpatients, including patients receiving kidney dialysis. Similar to many countries in the EU, Australia operates a reference pricing system [5]. Non-innovator products have to demonstrate a price advantage over existing agents.

Approach of the TGA to licensing of biosimilars

Almost as soon as the commercial advantages of licensing biosimilar drugs was noted in Europe, TGA moved to adopt key recommendations of the European Union. In August 2008, multiple EMA guidelines were reviewed and then adopted [6,7]. Although the number of drugs that have used the biosimilar licensing system in Australia is small so far, the system clearly works as planned. One potential reason for the small number of biosimilars licensed in Australia is the small size of the market, with the population reaching 23 million only recently.

\section{Epoetin biosimilars}

There are currently five epoetins registered for reimbursment on the PBS in Australia; epoetin alpha (Eprex, Janssen-Cilag), epoetin beta (Aranesp, Roche), darbepoetin (Amgen), epoetin lambda (Novicrit, Novartis), and methoxy polyethylene glycol-epoetin beta (Mircera, Roche) [8]. Of these, only epoetin lambda is a biosimilar. Although accepted as a biosimilar to epoetin alpha, TGA insisted that it use a different International Nonproprietary Name (INN) to distinguish it from that product, reasoning that glycosylation could not be demonstrated to be identical. The new INN is only used in Australia. As in other jurisdictions, Novicrit is restricted to intravenous use due to the absence of data supporting the safety of subcutaneous use. The drug was considered not to be interchangeable with other epoetins, primarily for this reason. 
TGA has also approved two different concentrations of epoetin lambda produced by Sandoz-Azicrit and Grandicrit. They have not yet been listed by PBS.

\section{G-CSF biosimilars}

There are three innovator products for G-CSF available on PBS in Australia, namely filgrastim (Neupogen, Amgen), lenograstim (Granocyte, Hospira) as well as pegfilgrastim (Neulasta, Amgen) [8]. Lenograstim is a glycosylated protein produced in Chinese hampster ovary (CHO) cells possessing the same amino acid sequence as the non-glycosylated filgrastim apart from an N-terminal methionine not present in the mature human protein. TevaGrastim (Aspen), Nivestim (Hospira) and Zarzio (Sandoz) were licensed by the TGA as biosimilars to filgrastim. They were produced in bacteria, as is Neupogen, and have the same INN, due to the absence of glycosylation and an identical amino acid sequence. Tevagrastim and Nivestim have PBS listing but Zarzio is not yet listed.

Data concerning TGA approvals and PBS listing can be obtained at: www.ebs.tga. gov.au and www.pbs.gov.au/browse/ medicine-listing respectively.

\section{Funding of biosimilars on the PBS}

As pointed out by Dr Teresa Nicoletti [9], the ability of pharmacists to substitute drugs off patent with their cheaper generics is a key factor in the success of the generics market. In Australia, there are two levels of reimbursement for pharmaceuticals. For novel, one-off products, they are placed on the F1 formulary by the PBS and priced at a level reflecting their ability to improve length or quality of life. Drugs with generic or biosimilar competitors are moved to the F2 formulary, where generics can be used to substitute without reference to the prescriber, provided the physician has not stipulated that a particular product be used [9].

In the case of the biosimilars, this creates a difficulty. Firstly, as noted above, the TGA has refused to permit use of the same INN for a biosimilar product. Therefore, it appears that some biosimilars will have to be prescribed by specific names, either commercial or INN, for use to occur in Australia. Pharmacists can substitute many pharmaceutical products in Australia on Formulary 2 without reference to the prescribing physician, provided the physician has not stipulated the exact preparation to be used. For biosimilars, this is not an option. The PBS has so far not agreed to give biosimilar products on the F2 formulary an 'a' label, which would indicate free substitution [9].

Where the products have the same INN names, as for filgrastim, and the prescriber uses the generic drug name, the pharmacist is free to choose any of the products with that name. If the prescriber uses the product name, then there is no automatic substitution. The onus for increased use of biosimilars and cheaper prescribing, therefore, falls on the physician.

\section{Supply of biosimilars and competitors to hospital pharmacies}

Many of these expensive biologicals are prescribed from a hospital pharmacy. For some classes, such as epoetin, they also require the prescribing physician to be a member of a particular specialty, a nephrologist in the case of epoetin, for example. These conditions and the specialist nature of the medications mean that the bulk of prescription is done by hospitals. Where there are several potential drugs for the one indication, as is the case with filgastim and epoetin, the hospital pharmacy is able to restrict supply to one drug, provided the prescribing physicians will accept a limitation on the drugs available. In Europe, such practices are common and lead to a competitive tendering process, sometimes on a countrywide basis, e.g. UK. In Australia, this has generally occurred only in specific hospitals, which have tendered out supply of certain classes of expensive drugs. The drug is reimbursed by PBS at the original price but the hospital receives a discount provided they can order in bulk. The practice has probably done much to reduce the price of biological drugs to direct suppliers in the Australian market, but at the cost of reduced choice for prescribers.

How important the availability of several drugs with identical mechanisms of action might be to prescribers is unclear. Anecdotally, prescribers in Australia have varied in their assessment of the importance of restrictions in the number of drugs available with many hospital physicians seeming to support the practice of bulk purchase. Importantly, companies marketing some of the original products, both innovator drug and approved non-innovator drugs, appear willing to compete on price. Tendering for contracts to supply drugs for a particular indication, such as renal anaemia, has lead to significant price competition between innovator drugs and their therapeutic rivals in Australia.

\section{Dispensing of biosimilars by community pharmacies}

When protein therapies such as epoetin and filgrastim first became available, they were dispensed through hospital pharmacies. This is still the place where the bulk of these drugs are supplied to patients. More recently, PBS has permitted community pharmacies to dispense these drugs. The improved convenience for patients able to access prescriptions of these items close to home is obvious. These pharmacies, of course, have no ability to reduce the price of the biological drug, as the hospitals can. Since PBS does not permit automatic substitution of biosimilars with different INN, pharmacists are unable to substitute a glycosylated biosimilar for its (presumably more expensive) comparator drug. Where the drug has the same INN, then the cheapest product can be supplied unless the prescribers stipulates use of a particular brand.

Another area of concern is whether the use of community pharmacies would affect tracking of batches if a drug proved to have problems, and whether patients would recall where their supply had come from. At present, it is not known how batch tracking could occur through community pharmacies.

\section{Conclusion}

Although the number of biosimilars in the Australian market is small, processes for licensing appear robust. There is increasing competition based on price, significantly between innovator drugs that are off patent and approved non-innovator drugs or biosimilars. This has come about through the ability of individual hospital pharmacies to limit choice of biologicals and tender for supply, and this is one area where considerable savings can occur. It is interesting that companies supplying established drugs, whether innovator products off patent or innovator drugs with similar mechanisms of action, e.g. darbepoetin versus epoetin alpha or beta, have been willing to compete aggressively on price.

Community pharmacies are increasingly involved in supply of biologicals, including biosimilars, but the convenience to the patient might be outweighed by lack of price competition and potential difficulties 
in tracking batches when adverse events occur. Increased dispensing by these pharmacies has the potential to dilute the financial benefit of biosimilars and multiple forms of similar drugs.

Finally, in at least one instance, the Australian TGA has ruled that glycosylated peptides from two manufacturers cannot share the same INN name, whereas non-glycosylated peptides are free to do so. Whether this will translate into a worldwide practice is not known.

Competing interests: Prior to 2008, Professor David Power received travel grants from Amgen, and research grants from Amgen and Janssen-Cilag. Over the last five years, Professor David Power has not received any research grants from commercial companies, but has received travel grants from Amgen, as well as honoraria from Amgen, Astra-Zeneca, Boehringer, KAI and Servier.
Since 2011, no further travel grants to international meetings have been accepted. He has travelled to a company- sponsored meeting concerning biosimilars in 2012.

Provenance and peer review: Commissioned; externally peer reviewed.

\section{References}

1. Ebbers HC, Crow SA, Vulto AG, Schellekens H. Interchangeability, immunogenicity and biosimilars. Nat Biotechnol. 2012;30(12):1186-90.

2. Casadevall N, Edwards IR, Felix T, Graze PR, Litten JB, Strober BE, et al. Pharmacovigilance and biosimilars: considerations, needs and challenges. Expert Opin Biol Ther. 2013 2013;Jul;13(7):1039-47.

3. Simoens S. Cost-effectiveness of pharmacotherapy for COPD in ambulatory care: a review. J Eval Clin Pract. 2013 Apr 17. [Epub ahead of print]

4. Minghetti P, Rocco P, Del Vecchio L, Locatelli F. Biosimilars and regulatory authorities. Nephron Clin Pract. 2011;117(1):c1-7.
5. Searles A, Jefferys S, Doran E, Henry DA Reference pricing, generic drugs and proposed changes to the Pharmaceutical Benefits Scheme. Med J Aust. 2007;187(4):236-9.

6. Roger SD. Biosimilars: how similar or dissimilar are they? Nephrology (Carlton). 2006;11(4):341-6.

7. GaBI Online - Generics and Biosimilars Initiative. Global biosimilars guideline development - EGA's perspective. [www.gabionline.net]. Mol, Belgium: Pro Pharma Communications International; [cited 2013 Jun 5]. Available from: www.gabionline. net/Guidelines/Global-biosimilars-guidelinedevelopment-EGA-s-perspective

8. Australian Government Department of Health and Ageing. Pharmaceutical Benefits Scheme (PBS) [homepage on the Internet]. 2013 [cited 2013 Jun 5]. Avaiable from: http://www.pbs.gov.au

9. Nicoletti T. Regulation and PBS pricing of biosimilar drugs. Lexology. 2011 [cited 2013 Jun 5]. Available from: http://www.lexology.com/library/detail.aspx? g=b7f04d06-8be5-4a70-995a-1f31ad5e4a56

DOI: 10.5639/gabij.2013.0203.030

Copyright $\odot 2013$ Pro Pharma Communications International 